\title{
Influence of $\operatorname{prgH}$ on the Persistence of Ingested Salmonella enterica in the Leafhopper Macrosteles quadrilineatus
}

\author{
José Pablo Dundore-Arias, ${ }^{a}$ Russell L. Groves, ${ }^{b}$ Jeri D. Barak ${ }^{a}$

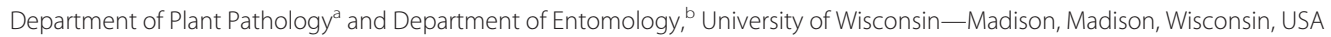

Phytophagous insects can encounter Salmonella enterica on contaminated plant surfaces and transmit externally adhered and internalized bacteria on and among leaves. Excretion of ingested S. enterica by the leafhopper Macrosteles quadrilineatus has been previously reported; however, the sites of persistence of ingested bacteria remain undetermined. Fluorescence microscopy revealed the presence and persistence of S. enterica in various organs of M. quadrilineatus fed an inoculated diet for $12 \mathrm{~h}$ and then moved to two consecutive noninoculated diets for a total of $48 \mathrm{~h}$. Ingested $S$. enterica was predominantly observed in the filter chamber, midgut, and Malpighian tubules of M. quadrilineatus dissected immediately after acquisition and at 24- and 48-h post-acquisition access periods (post-AAPs). Additionally, we examined the potential roles of the Salmonella pathogenicity island 1 (SPI-1) and SPI-2 type III secretion systems (T3SSs) in the persistence and excretion of ingested S. enterica. In competition assays, a prgH mutant lacking a functional SPI-1 T3SS was recovered at significantly lower levels than the WT in insect homogenates at $24 \mathrm{~h}$ post-AAP, and complementation with prgH restored S. enterica persistence in M. quadrilineatus. Moreover, expression of $\mathrm{prgH}$ inside $\mathrm{M}$. quadrilineatus was observed up to 48 post-AAP. No differences were observed between the WT and an ssaK mutant lacking a functional SPI-2 T3SS in insect homogenates or between the WT and either mutant in insect excretions. This study provides novel insight into the presence and persistence of S. enterica inside M. quadrilineatus and demonstrates that the SPI-1 T3SS influences the persistence of the pathogen in the gut of a potential vector.

Calmonella enterica is the leading cause of bacterial foodborne illness in the United States (1). In the last few decades, salmonellosis outbreaks attributed to $S$. enterica-contaminated fresh produce have increased, and produce is now considered the most likely vehicle of disease transmission (2). Plant contamination with $S$. enterica is thought to primarily occur in the field before harvest, and the pathogen has the ability to adhere, colonize, and persist in and on plant surfaces, in some cases for extended periods $(3,4)$. Domestic and wild animals represent one of the main entry routes for $S$. enterica to produce fields, where they can directly introduce the bacterial pathogens to plants or agricultural water through excretion of contaminated waste (3). Additionally, synanthropic and coprophagic insects can introduce human bacterial pathogens to produce fields by dispersing bacteria associated with their exoskeletons onto plant surfaces (5). These events increase the chances that phytophagous insects could encounter a human enteric pathogen as a result of feeding or wandering on contaminated plant surfaces. The abundance and distribution of phytophagous insects within agricultural fields suggest that their contamination could influence the dispersal of enteric pathogens in the field (6).

The aster leafhopper, Macrosteles quadrilineatus Forbes (Hemiptera: Cicadellidae), is an important agricultural pest of several fresh vegetable crops that have been linked to foodborne illness outbreaks (7). Previous studies demonstrated that $M$. quadrilineatus can become contaminated with S. enterica after feeding on contaminated plant material, and plant infestation with these insects enhanced the persistence of the pathogen on lettuce (8). M. quadrilineatus can also transmit externally attached and ingested bacteria to noninoculated leaves or artificial diets, thereby serving as vectors of S. enterica (6). One route of transmission of ingested bacteria was excretion of ingested S. enterica in honeydew, a sugar-rich secretion deposited in large volumes on plant surfaces by phloem sap-feeding insects. However, the status and sites of persistence of ingested S. enterica within M. quadrilineatus, and the molecular and biochemical underpinnings of these interactions, remain undetermined.

Members of the family Enterobacteriaceae, which contains $S$. enterica, have an intimate association with insects, exploiting them as alternate hosts or vectors or acting as pathogens or symbionts $(9,10)$. Many of these bacteria employ type III secretion systems (T3SSs), similar to those used by mammalian and plant pathogens during pathogenesis, to establish associations with insects. These secretion systems act as a molecular syringe that allows bacteria to deliver effector proteins necessary for multiple purposes, including host invasion, defense suppression, and pathogen multiplication within host cells (11). Phylogenetic analyses have identified seven distinct families of T3SSs, including the SPI-1 (also known as Inv-Mxi-Spa) and SPI-2 (also known as Ssa-Esc) families, associated with animal pathogens, and the Rhizobiales, Hrp1, and Hrp2 families, associated with plant pathogens (11). Some bacterial pathogens have multiple T3SSs from different families, and each of them is required at different points during interactions with their host. S. enterica has two T3SSs, Salmonella pathogenicity island 1 (SPI-1), required for host cell penetration, and SPI-2, important for subsequent intracellular

Received 5 May 2015 Accepted 30 June 2015

Accepted manuscript posted online 6 July 2015

Citation Dundore-Arias JP, Groves RL, Barak JD. 2015. Influence of prgH on the persistence of ingested Salmonella enterica in the leafhopper Macrosteles quadrilineatus. Appl Environ Microbiol 81:6345-6354. doi:10.1128/AEM.01464-15. Editor: H. L. Drake

Address correspondence to Jeri D. Barak, jeri.barak@wisc.edu. Copyright @ 2015, American Society for Microbiology. All Rights Reserved. doi:10.1128/AEM.01464-15 
TABLE 1 S. enterica strains and plasmids used in this study

\begin{tabular}{|c|c|c|}
\hline Strain or plasmid & Genotype or relevant characteristics & $\begin{array}{l}\text { Source or } \\
\text { reference }\end{array}$ \\
\hline \multicolumn{3}{|l|}{ Strains } \\
\hline $14028 s$ & Wild type & ATCC \\
\hline JDB1034 & Wild type spontaneously resistant to $\mathrm{Nal}$ & This study \\
\hline JDB1253 & 1034 wild-type-pKT-kan & This study \\
\hline JDB1254 & 1034 prgH-pProbeNT & This study \\
\hline JDB1256 & 14028s $\Delta p r g H:: \operatorname{Kan}^{\mathrm{r}}$ & This study \\
\hline JDB1257 & 14028s $\Delta \operatorname{prgH}:: \mathrm{Cm}^{\mathrm{r}}$ & This study \\
\hline JDB1258 & 14028 s $\Delta s s a K:: \operatorname{Kan}^{\mathrm{r}}$ & This study \\
\hline JDB1261 & $\begin{array}{l}\text { 14028s } \Delta p r g H:: \mathrm{Cm}^{\mathrm{r}} \text { prgH-pEVS } \\
\quad \text { (complement) }\end{array}$ & This study \\
\hline JDB1262 & 14028s $\Delta p r g H:: \mathrm{Cm}^{\mathrm{r}}$-pKT-kan & This study \\
\hline JDB1279 & 14028s $\Delta p r g H:: \mathrm{Cm}^{\mathrm{r}}$-pEVS143 empty & This study \\
\hline \multicolumn{3}{|l|}{ Plasmids } \\
\hline pKT-kan & $g f p$ expression and Kan resistance & 17 \\
\hline pProbe-NT & $g f p$ reporter & 18 \\
\hline pEVS143 & $\begin{array}{l}\text { Broad-host-range cloning vector; Kan } \\
\text { resistance }\end{array}$ & 50 \\
\hline
\end{tabular}

proliferation (12). Similarly, the endosymbiont Sodalis glossinidius of the tsetse fly (Glossina palpalis) contains two distinct SPI-1 T3SSs, one required for invasion of host cells and the second required for bacterial survival after entry (13). Interestingly, the plant-pathogenic bacterium Pantoea stewartii, the causal agent of Stewart's wilt of corn (Zea mays L.), also possesses two T3SSs, an Hrp1 required for plant pathogenesis and an SPI-1 required for bacterial persistence in the corn flea beetle (Chaetocnema pulicaria) vector and for subsequent transmission to host plants (14). Thus, although the SPI- 1 of S. enterica is best known for its role in mammalian pathogenesis, it is possible that it is important in interactions with insect vectors. The role of T3SSs in S. enterica interactions with mammalian and plant hosts has been previously described $(15,16)$. However, the role of T3SSs in S. enterica-insect interactions remains unknown.

The main objective of this study was to investigate the acquisition of S. enterica and to determine the sites of persistence within M. quadrilineatus. We hypothesize that $S$. enterica establishes a temporary association with phytophagous insects that enhances the bacterium's epiphytic survival on plants and movement between plants. To test this hypothesis, we examined S. enterica persistence within $M$. quadrilineatus following acquisition using fluorescence microscopy. Furthermore, we investigated a possible role for the two T3SSs, SPI-1 and SPI-2, in the presence, persistence, and excretion of ingested $S$. enterica. The results of this study suggest that a functional SPI-1 T3SS needle complex is required in bacterium-hemipteran interactions, allowing the pathogen to persist within phytophagous insects, which to this point had conventionally been considered nonhosts.

\section{MATERIALS AND METHODS}

Bacterial strains, media, and culture conditions. The bacterial strains and plasmids used in this study are listed in Table 1. All strains were grown in, or plated on, Luria-Bertani (LB) medium. Media were amended with the following antibiotics as necessary: kanamycin (Kan) $(50 \mu \mathrm{g} / \mathrm{ml})$, chloramphenicol (Cm) $(20 \mu \mathrm{g} / \mathrm{ml})$, or nalidixic acid (Nal) $(50 \mu \mathrm{g} / \mathrm{ml})$.

Generation of fluorescent $S$. enterica strains. Plasmid pKT-kan was transformed into wild-type (WT) S. enterica JDB1034 (WT-pKT-kan) and $\Delta p r g H$ JDB1257 ( $\Delta p r g H:: \mathrm{Cm}^{\mathrm{r}}$-pKT-kan); this plasmid confers Kan resistance and green fluorescent protein (GFP) gene $(g f p)$ expression and has been shown to have no effect on the survival and growth of $S$. enterica $(17,18)$.

Generation of the $S$. enterica prgH pProbeNT strain. Additionally, the putative promoter region of the $\mathrm{prgH}$ gene was PCR amplified from $S$. enterica $14028 \mathrm{~s}$ using primers prgHForXbal (NNNTCTAGATAAGTTAT CTGCGGCAGG) and prgHRevEcoRI (NNNGAATTCCCTGGGCTTGT TATCGTC), digested with EcoRI/XbaI, and cloned into pProbeNT (18). All constructs were confirmed and the promoter orientations were determined by sequencing (Quintara Biosciences, Berkeley, CA), and the prgH pProbeNT construct was electroporated into S. enterica JDB1034. Plasmid uptake by $S$. enterica JDB1034 was confirmed by plating the transformed strains (WT pKT-kan and prgH pProbeNT) on Kan-amended media, and these strains were used in the insect-feeding and confocal-imaging assays described below. The constitutive expression of $g f p$ was seen in all colonies of the WT pKT-kan strain grown on LB plates by visualizing bright-green fluorescence through microscopy or by naked eye under UV light in the dark. On the other hand, green fluorescence was not observed in colonies of the $p r g H$ pProbeNT strain grown on LB plates. To confirm that $g f p$ was constitutively expressed only in the WT pKT-kan strain and not in the $\operatorname{prgH}$ pProbeNT strain, fluorescence for each strain was measured. Briefly, JDB1034, JDB1253, and JDB1254 were grown overnight in LB medium at $37^{\circ} \mathrm{C}$ with agitation. Overnight cultures of each strain were diluted $1: 10$ and grown to an optical density (OD) of 1 , and 200- $\mu$ l aliquots were loaded into the wells of a 96-well plate. Additionally, serial dilutions of the WT pKT-kan strain $\left(10^{8}, 10^{6}, 10^{4}, 10^{2}\right.$, and $\left.10^{1}\right)$ were made and loaded into separate wells. Three replicate wells were included for each strain and dilution, as well as for the water control. Samples were incubated for 5 min, and endpoint fluorescence from each strain was measured at an excitation wavelength of $485 \mathrm{~nm}$ and an emission wavelength of $520 \mathrm{~nm}$, using a plate reader (Synergy HT; BioTek, Winooski, VT). Averages of the fluorescence values for the three replicates were calculated and used to compare fluorescence between the prgH pProbeNT, WT, and WT pKTkan strains. The fluorescence values of the undiluted $\operatorname{prgH}$ pProbeNT suspension (79 fluorescence units) were similar to those of the undiluted WT (24 fluorescence units) and the most diluted $\left(10^{2}\right.$ and $\left.10^{1}\right)$ WT-pKTkan suspensions (95 and 54 fluorescence units, respectively) but significantly lower than those of the undiluted WT-pKT-kan suspensions (582 fluorescence units). Therefore, it was considered that $g f p$ is not constitutively expressed in the $\mathrm{prgH}$ pProbeNT strain and exhibits fluorescence only when the $\mathrm{prgH}$ gene is expressed.

Generation of deletion mutants and complementing plasmids. The $\mathrm{prgH}$ and $s s a \mathrm{~K}$ mutants used in this study were taken from a deletion library generated by the lambda Red recombinase method in S. enterica serotype Typhimurium ATCC 14028s (19). To obtain isogenic strains and reduce the possibility of secondary mutations, each mutation was transduced with phage P22 into a clean 14028s background (20). The complemented strain was constructed by amplifying the $\mathrm{prgH}$ gene from $\mathrm{S}$. enterica 14028s using primers prgHForAvr (NNNCCTAGGGAGAACGAC AGACATCGC) and prgHRevBam (NNNGGATCCCCTGACCAAGGTG TTGCC). The amplicon was then digested with AvrII/BamHI, excised and purified from a 1\% agarose gel (QIAquick gel extraction kit; Qiagen Inc., Valencia, CA), and cloned into pEVS143, which is a medium-copy-number plasmid that confers Kan resistance. The presence of the correct insert was confirmed by sequencing (Quintara Biosciences, Berkeley, CA), and the corresponding plasmid was electroporated into the $\Delta p r g H:: \mathrm{Cm}^{\mathrm{r}} \mathrm{mu}-$ tant strain. Uptake of the plasmid by the $\Delta p r g H:: \mathrm{Cm}^{\mathrm{r}}$ strain was confirmed by PCR using primers to amplify the $\mathrm{prgH}$ gene and by plating the transformed strains ( $\Delta$ prgH:: $\mathrm{Cm}^{\mathrm{r}}$ prgH-pEVS) on Kan-amended media. Additionally, an empty plasmid, pEVS143, was electroporated into the $\Delta p r g H:: \mathrm{Cm}^{\mathrm{r}}$ mutant strain, and uptake of the plasmid by the $\Delta p r g H:: \mathrm{Cm}^{\mathrm{r}}$ strain was confirmed by plating the transformed strain $\left(\Delta p r g H:: \mathrm{Cm}^{\mathrm{r}}-\right.$ pEVS empty) on Kan-Cm-amended media. These strains (the prgH mutant, the complement, and the mutant transformed with the empty vec- 

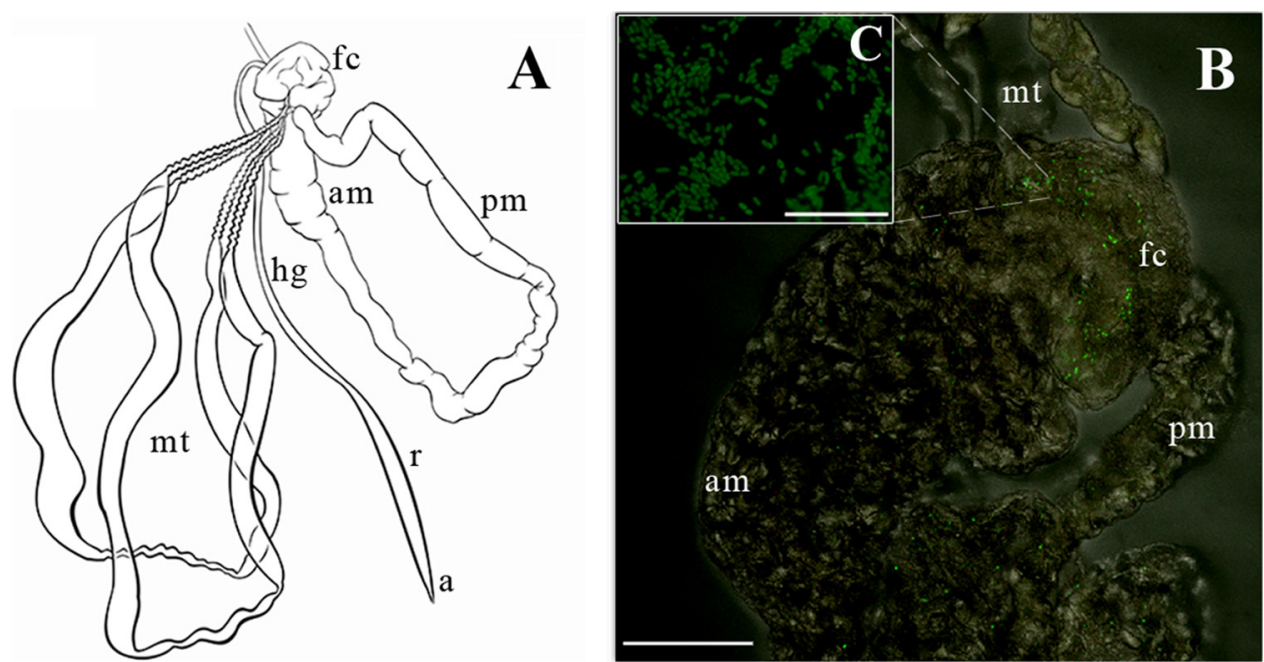

FIG 1 Presence of ingested S. enterica in the alimentary canal of M. quadrilineatus. (A) Diagram depicting the relative positions of the M. quadrilineatus filter chamber ( $\mathrm{fc}$ ), anterior midgut (am), posterior midgut (pm), Malpighian tubules (mt), hindgut (hg), rectum (r), and anus (a). (B) Confocal micrograph of dissected guts of an insect fed an S. enterica-inoculated liquid diet confined in Parafilm sachets following a 12-h AAP. (C) Representative close-up image of fluorescent S. enterica (green) in a dissected insect observed at higher magnification with an epifluorescence microscope. Fluorescent $S$. enterica bacteria are mainly present in the fc and throughout the am. The experiment was repeated 7 times, and a total of 54 insects were dissected and examined after the 12-h AAP. Scale bars, $100 \mu \mathrm{m}$.

tor) were used for complementation studies. To rule out the possibility that the mutant strains had general growth defects compared to the WT, growth kinetics in LB medium and minimal medium (M9) were determined for each strain. Bacteria were inoculated in LB medium with appropriate antibiotics for overnight growth at $37^{\circ} \mathrm{C}$ with agitation. Overnight cultures were used to prepare bacterial suspensions at an OD of 0.2 , which were then diluted 1:1,000, and 2- $\mu$ l aliquots of the diluted culture of each strain were transferred into the wells of a 96-well plate containing 200 $\mu$ l of LB medium. Similarly, undiluted cultures were transferred into wells containing $200 \mu \mathrm{l}$ of M9 medium. Three replicate wells were included for each strain, each medium, and the corresponding controls. Kinetic bacterial growth was recorded by reading the optical density at $600 \mathrm{~nm}$ $\left(\mathrm{OD}_{600}\right)$ every 30 min using a plate reader (Synergy HT; BioTek, Winooski, VT) at $37^{\circ} \mathrm{C}$ with continuous shaking for $48 \mathrm{~h}$. Averages of the $\mathrm{OD}_{600}$ values for the three replicates were calculated and used to compare growth phenotypes between the WT and the mutant strains. Additionally, after the 48-h incubation period, each culture was sampled, diluted $1: 10,000$, plated on LB medium and LB medium with antibiotics, and incubated overnight at $37^{\circ} \mathrm{C}$. Bacterial populations were enumerated and compared between media with and without antibiotics to make sure that the lack of antibiotic did not affect bacterial growth. There were no significant differences in growth kinetics for any of the strains (data not shown), suggesting that the cultures would grow at the same rate in the competition assays.

Insect feeding of fluorescent S. enterica. Adult M. quadrilineatus insects were collected from a colony maintained on oat (Avena sativa L.) seedlings as previously described (6). To visualize the presence and persistence of ingested S. enterica in the alimentary canal of M. quadrilineatus, individual insects were contained inside $1.5-\mathrm{ml}$ microcentrifuge tubes and fed a synthetic liquid diet through Parafilm sachets as previously described (6). Parafilm sachets were used to limit physical contact of the insect body with the liquid diet but allow oral ingestion. The liquid diets consisted of either GFP-fluorescent $S$. enterica (WT pKT-kan; $10^{6} \mathrm{CFU} / \mathrm{ml}$ ) or sterile water mixed at a 1:1 ratio with a $10 \%$ sucrose solution; insects were allowed to feed on these diets for a 12-h acquisition access period (AAP). After the 12-h AAP, the insects were anesthetized by placing the tubes in an ice bath for $10 \mathrm{~min}$ and individually transferred to two consecutive $S$. enterica-free liquid diets for a total of $48 \mathrm{~h}$ post-AAP. Specifically, adult insects were allowed access to each sachet for $24 \mathrm{~h}$. At the corresponding AAP and post-AAP, live insects were collected in sterile microcentrifuge tubes and stored at $4^{\circ} \mathrm{C}$ until processing for confocal microscopy. This experiment was repeated 7 times, and a total of 228 live insects ( 148 and 80 exposed and unexposed to $S$. enterica, respectively) were dissected and examined. A similar experiment was performed to visualize the presence and persistence of the $\Delta p r g H$ strain in the alimentary canal of M. quadrilineatus. This experiment was repeated 3 times, and 132 live insects (84 and 48 exposed and unexposed to $S$. enterica, respectively) were dissected and examined. The insects were fed a liquid diet inoculated with a GFPfluorescent $\Delta \operatorname{prgH}\left(\Delta \operatorname{prg} H:: \mathrm{Cm}^{\mathrm{r}}\right.$-pKT-kan) strain and sampled after either a 12-h AAP or a 24 - and a 48 -h post-AAP as described above. A supplementary set of experiments was conducted to determine whether prgH was expressed (GFP fluorescence) in the gut of M. quadrilineatus after acquisition. Following the procedures described above, the insects were fed a liquid diet consisting of either prgH pProbeNT S. enterica $\left(10^{6}\right.$ $\mathrm{CFU} / \mathrm{ml}$ ) or sterile water mixed at a 1:1 ratio with a $10 \%$ sucrose solution, and insects were sampled after a $12-\mathrm{h} \mathrm{AAP}$ and a 24 - and a 48 -h post-AAP. This experiment was repeated 5 times, and a total of 182 live insects (122 and 60 exposed and unexposed to prgH pProbeNT S. enterica, respectively) were dissected and examined. In both experiments (with GFPfluorescent and with $\operatorname{prgH}$ pProbeNT S. enterica), additional insects were collected at each time point and individually transferred to new, sterile microcentrifuge tubes and placed at $-80^{\circ} \mathrm{C}$ to kill them without affecting the potential ingested S. enterica, and then they were homogenized in 100 $\mu \mathrm{l}$ of sterile water as previously described (6). Insect homogenate samples were then plated on LB-Kan (see below) to verify the presence of viable $S$. enterica in insect bodies.

Insect dissection and microscopy. Live M. quadrilineatus insects were dissected under a dissecting microscope in $1 \times$ phosphate-buffered saline (PBS) solution ( $\mathrm{pH} 7.4$ ); using two fine-tip forceps, the head was cut, and then the rear end of the abdomen, with the hindgut, midgut, and part of the foregut attached to it, was gently pulled backward in a single motion. The dissected organs were fixed in $4 \%$ paraformaldehyde overnight and washed with $\mathrm{PBS}$ three times for $10 \mathrm{~min}$ each time at $4^{\circ} \mathrm{C}$ on a rotator device. The fixed tissues were carefully mounted on microscope slides in ProLong Gold Antifade mounting medium (Thermo Fisher Scientific Inc.), protected from light as much as possible, and examined using a 

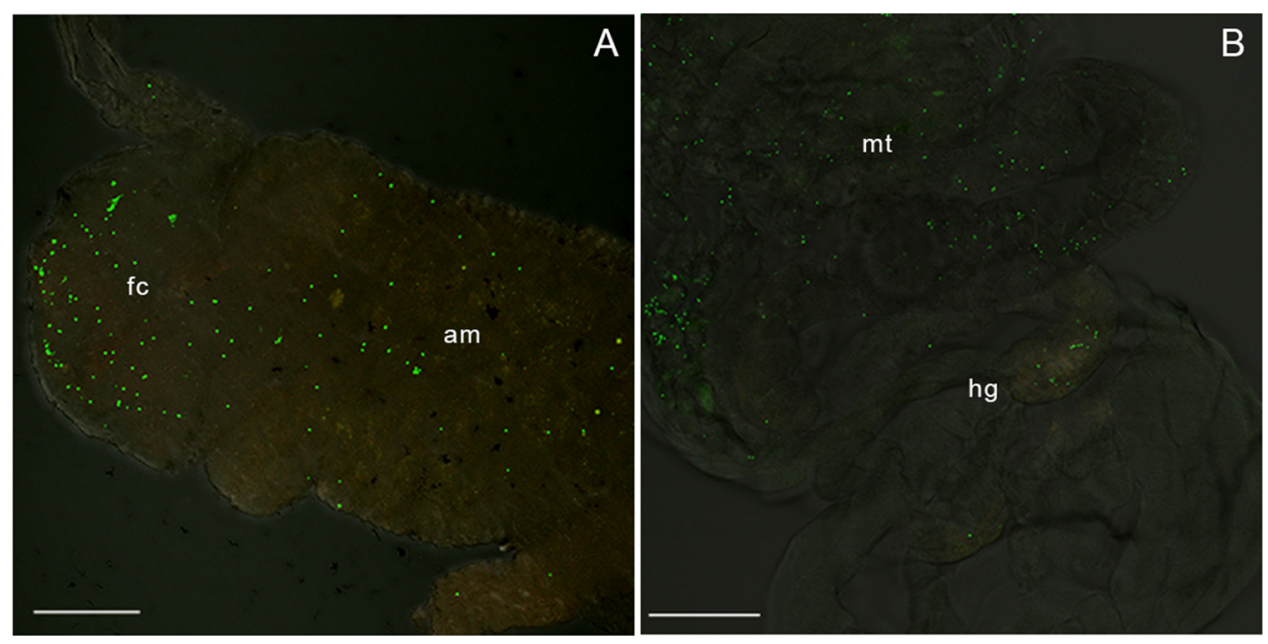

FIG 2 Persistence of ingested S. enterica in the alimentary canal of $M$. quadrilineatus. Shown are confocal micrographs of dissected guts of insects that were fed an S. enterica-inoculated liquid diet confined in Parafilm sachets for a 12-h acquisition access period and then moved to two consecutive noninoculated liquid diets for two 24-h post-AAPs each. Fluorescent S. enterica (green) was observed in the filter chamber (fc) and the anterior midgut (am) at the 24-h post-AAP (A) and in the hindgut (hg) and Malpighian tubules (mt) at the 48-h post-AAP (B). The experiment was repeated 7 times, and a total of 46 and 48 insects were dissected and examined at the 24 - and 48 -h post-AAPs, respectively. Scale bars, $100 \mu \mathrm{m}$.

Nikon A1R (Fig. 1A and B and 2) or a Leica SP8-X (see Fig. 5) confocal microscope. From each experiment, a subset of samples was also examined with an Olympus BX-60 epifluorescence microscope (Opelco, Dulles, VA) to ensure that fluorescent bacteria were present in the samples after tissue fixation and before confocal microscopy (Fig. 1C). Fluorescence was not observed in insects fed a noninoculated diet, independent of the strain used or sampling time (data not shown).

Competition assay. To examine the roles of T3SS SPI-1 and SPI-2 genes in S. enterica persistence inside the insect, $M$. quadrilineatus insects were fed an artificial liquid diet consisting of a $10 \%$ sucrose solution mixed with equal populations of the WT strain (JDB1034) and a mutant with the gene of interest deleted $\left(\Delta p r g H:: \operatorname{Kan}^{\mathrm{r}}\right.$ or $\left.\Delta s s a K:: \operatorname{Kan}^{\mathrm{r}}\right)$ in a $1: 1$ ratio. Both $\mathrm{prgH}$ and $s s a K$ are required to inject effector proteins into host cells and therefore for virulence in animal hosts $(21,22)$. The ratio of WT to mutant bacteria in the inoculum was verified by viable counts after plating serial dilutions of the inoculum on LB medium amended with the corresponding antibiotic (Nal for the WT and Kan for mutants). Following the procedures described above, individual insects were fed liquid diets $\left(10^{6} \mathrm{CFU} / \mathrm{ml}\right)$ through Parafilm sachets for a 24 -h AAP and then transferred to $S$. enterica-free liquid diets for a 24 -h post-AAP. Bacterial populations of both strains (the WT and the corresponding mutant), which carried distinct antibiotic markers, were enumerated from homogenized insects at a 24 -h post-AAP (as described above) and from honeydew samples collected at the 24-h AAP and 24-h post-AAP time points (6). Specifically, honeydew and homogenized insect samples were dilution plated on LB-Nal (WT) and LB-Kan (mutant) to enumerate the bacterial populations. Samples were also enriched in antibiotic-amended medium in order to improve the sensitivity in detecting $S$. enterica in samples containing the pathogen even at very low concentrations. The bacterial population in samples that were negative after direct plating but positive after enrichment was arbitrarily determined as $1 \mathrm{CFU}$. These experiments were repeated 4 times $(n=56$ insects) and 3 times $(n=40$ insects) for the WT-prgH mutant and WT-ssaK mutant comparisons, respectively. Complementation studies were performed following the same procedures to compare the WT to the $\mathrm{prgH}$ mutant and the complemented strain $\left(\Delta p r g H:: \mathrm{Cm}^{\mathrm{r}} \operatorname{prgH}\right.$-pEVS) and an empty-vector control $\left(\Delta p r g H:: \mathrm{Cm}^{\mathrm{r}} \mathrm{pEVS}\right)$. These experiments were repeated 4 times each, and 50,48 , and 60 insect homogenate samples were evaluated for the WTprgH mutant, WT-prgH complement, and WT-prgH empty-vector comparisons, respectively. The competitive index (CI) was determined as the difference between the WT population $(\log \mathrm{CFU} / \mathrm{ml})$ and the compared strain (deletion mutants, complement, or empty vector) for each sample. In this case, a difference instead of a ratio was calculated because in some cases, either the WT or another strain was not recovered from honeydew or insect homogenate samples. A mean CI of 0 denotes no difference between the two population sizes.

Statistical analysis. Consistently, S. enterica was not recovered from noninoculated control insect homogenate or honeydew samples in any of the experiments; therefore, these data are not shown. No significant differences were found among replications of the overall experiments; thus, means from all the replicates of each experiment were combined. Statistical significance was determined by a paired $t$ test relative to the CI determined for a competition between the WT population and the mutant strain population recovered from either honeydew or insect homogenate samples and by a one-sample $t$ test to determine whether the mean CI differed significantly from a CI of 0 (no competitive difference between the WT and the compared strain). Moreover, McNemar's test was used to test for marginal homogeneity in contamination rates over time, based on the number of honeydew and insect homogenate samples testing positive for S. enterica at the 24-h AAP or the 24-h post-AAP. Comparisons were made based on individual M. quadrilineatus insects fed mixed inocula of $S$. enterica TTSS mutants and the WT. This approach is commonly applied as a normal approximation on paired, nominal data expressed as a dichotomous trait, with matched pairs of subjects, and is designed to determine whether marginal detection frequencies are equal. All statistical analyses were performed using R software version 2.14.1 (http://www.r-project .org).

\section{RESULTS}

Presence and persistence of S. enterica in the alimentary canal of M. quadrilineatus. To investigate the presence of ingested S. enterica within $M$. quadrilineatus, insects $(n=148)$ were dissected after feeding on a liquid diet inoculated with GFP-labeled $S$. enterica (WT pKT-kan) following a 12-h AAP or after being transferred to sterile microcentrifuge tubes and fed a noninoculated liquid diet for 24 or $48 \mathrm{~h}$ post-AAP. Insects were dissected with the purpose of evaluating the postacquisition persistence of ingested $S$. enterica within the alimentary canals of adult $M$. quadrilineatus insects. S. enterica was observed in $77 \%$ of insects sampled after 
TABLE 2 Mean proportions of gut dissections in which ingested fluorescent S. enterica was observed in M. quadrilineatus

\begin{tabular}{|c|c|c|c|}
\hline Strain & Sampling time ${ }^{a}$ & $\begin{array}{l}\text { Total no. of } \\
\text { insects } \\
\text { sampled }\end{array}$ & $\begin{array}{l}\text { Proportion of insect } \\
\text { guts with } \\
\text { fluorescent } S \text {. } \\
\text { enterica }^{b}\end{array}$ \\
\hline \multirow{3}{*}{ Wild-type-pKT-kan } & 12-h AAP & 54 & $0.77 \pm 0.09$ \\
\hline & 24-h post-AAP & 46 & $0.29 \pm 0.07$ \\
\hline & 48-h post-AAP & 48 & $0.38 \pm 0.13$ \\
\hline \multirow[t]{3}{*}{$\Delta p r g H:: \mathrm{Cm}^{\mathrm{r}}$-pKT-kan } & 12-h AAP & 32 & $0.31 \pm 0.04$ \\
\hline & 24-h post-AAP & 24 & $0.08 \pm 0.06$ \\
\hline & 48-h post-AAP & 28 & $0.06 \pm 0.04$ \\
\hline \multirow[t]{3}{*}{ prgH-pProbeNT } & 12-h AAP & 34 & $0.35 \pm 0.10$ \\
\hline & 24-h post-AAP & 44 & $0.16 \pm 0.05$ \\
\hline & 48-h post-AAP & 44 & $0.18 \pm 0.08$ \\
\hline
\end{tabular}

${ }^{a}$ Insects were fed an inoculated liquid diet for a 12-h acquisition access period (AAP) and then fed two consecutive noninoculated liquid diets for $24 \mathrm{~h}$ post-AAP each.

${ }^{b}$ Proportions are reported as mean proportion \pm standard error.

the 12 -h AAP and in $29 \%$ and $38 \%$ of the insects sampled after the 24- and 48-h post-AAPs, respectively (Table 2). Dissection and reference to the internal anatomy of other leafhopper species (23) allowed us to make detailed illustrations of the poorly described digestive tract of M. quadrilineatus (Fig. 1), which were used as reference points while identifying the organs containing fluorescent S. enterica. Confocal imaging of the dissected guts showed aggregates and single cells of S. enterica distributed along the alimentary canal of $M$. quadrilineatus. In insects dissected after the 12-h AAP, S. enterica was regularly observed in specific portions of the alimentary canal, such as the filter chamber and anterior midgut (Fig. 1). Close examination revealed both single cells and small aggregates. Modest aggregates of fluorescent bacteria were also observed in the filter chamber, as well as the anterior and posterior midgut regions, of insects dissected after the 24 -h postAAP (Fig. 2). In insects dissected after the 48-h post-AAP, bacteria were found mainly in the hindgut and Malpighian tubules, the insect renal system, and very few were observed in the midgut (Fig. 2 ). These results demonstrate the presence of ingested S. enterica predominantly in the middle and posterior parts of the alimentary canal of $M$. quadrilineatus and persistence inside the insect for up to $48 \mathrm{~h}$ post-AAP. The passage of $S$. enterica in the alimentary canal of $M$. quadrilineatus appears to proceed from the filter chamber and anterior midgut to the posterior midgut to the hindgut and Malpighian tubules.

The SPI-1 T3SS is important for persistence of S. enterica in the alimentary canal of $M$. quadrilineatus. CI analysis is a popular method in Salmonella-animal model research that uses mixed infections to determine virulence attenuation caused by a given mutation (24). To evaluate the potential role of SPI-1 and SPI-2 T3SSs in S. enterica persistence inside $M$. quadrilineatus, we determined the CI of the WT versus the $\Delta p r g H$ (SPI-1) and the WT versus the $\Delta s s a K$ (SPI-2) strains by comparing the populations of viable cells of each strain recovered from either honeydew or insect homogenate samples. No differences were observed between the WT and the $\operatorname{prgH}$ mutant populations in honeydew samples collected immediately after acquisition (AAP) or $24 \mathrm{~h}$ later (postAAP) (Fig. 3A). However, the prgH mutant was recovered at sig-
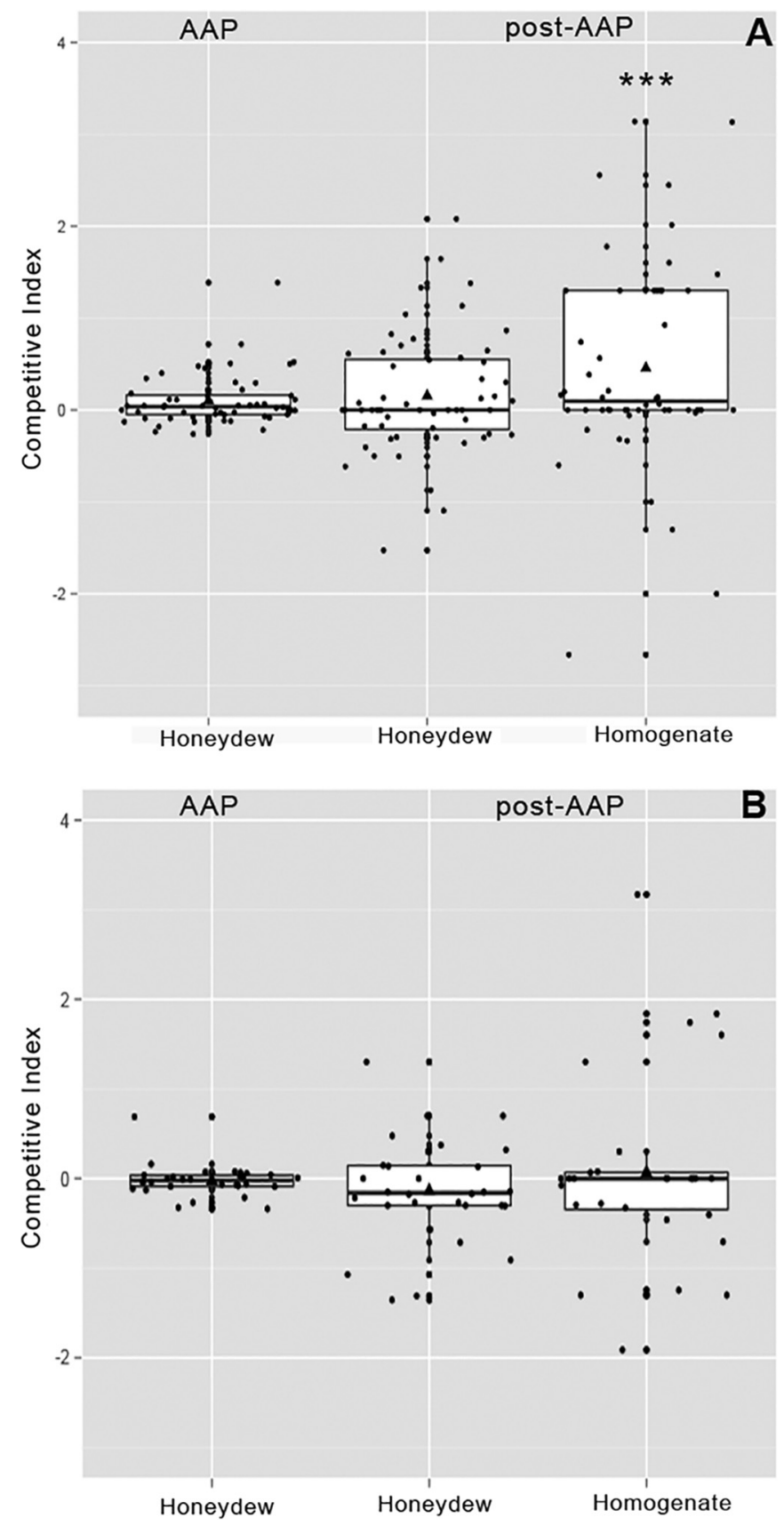

FIG 3 Competition assay in $M$. quadrilineatus fed mixed inocula of S. enterica WT and the prgH mutant (A) or the WT and the ssaK mutant (B). Insects were fed an inoculated liquid diet confined in Parafilm sachets for a 24-h AAP and then moved to a noninoculated liquid diet for a 24 -h post-AAP. Bacteria were recovered from the honeydew at the 24-h AAP and 24-h post-AAP and from insect homogenates at the 24 -h post-AAP. The sizes of the boxes are determined by the 25th and 75th percentiles, and the horizontal line and triangle within each box represent the median and mean, respectively. The CI represents the difference between the WT and the mutant strain populations (log CFU per milliliter). A mean CI (triangle) significantly different than $0(* * *$, $P<0.05)$ denotes a competitive difference between the WT and the mutant. The data shown are from 4 ( $n=56$ samples) (A) and 3 ( $n=40$ samples) (B) independent, experimental replications. 


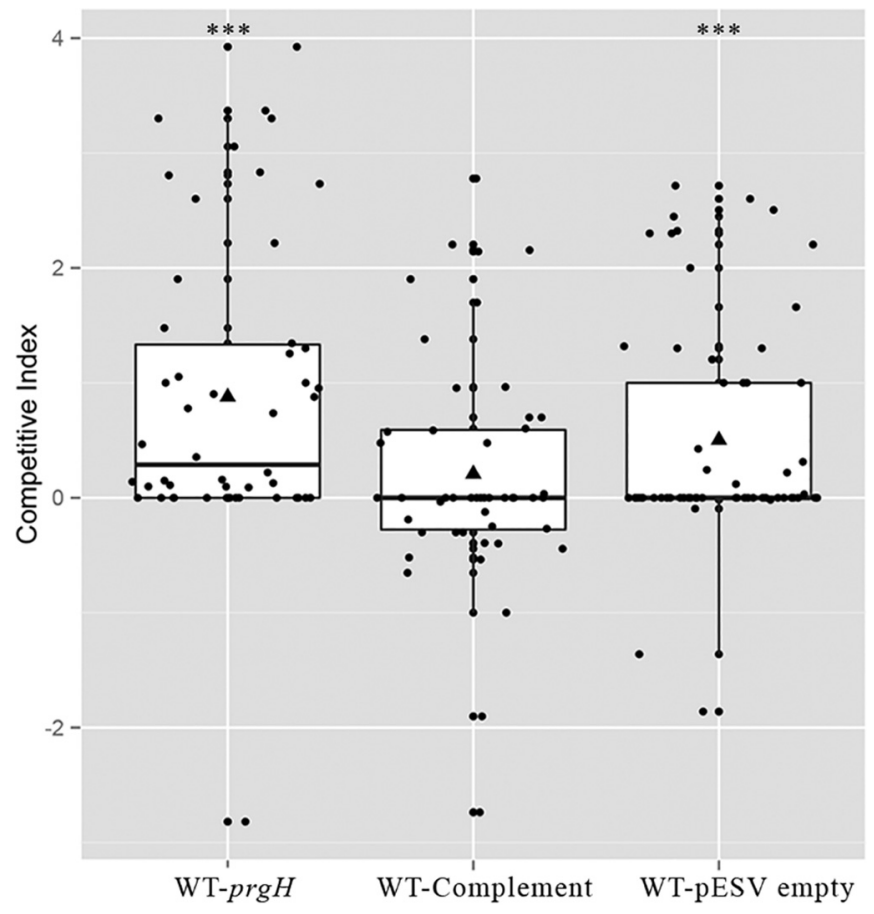

FIG 4 Competition assay in $M$. quadrilineatus fed mixed inocula of $S$. enterica WT and $\operatorname{prgH}$ mutant, WT and $\operatorname{prgH}$ complement strain, or WT and $\operatorname{prgH}$ transformed with empty pESV143 vector. The insects were fed an inoculated liquid diet confined in Parafilm sachets for a 24-h AAP and then moved to a noninoculated liquid diet for a 24 -h post-AAP. Bacteria were recovered from insect homogenates at the 24-h post-AAP. The size of the box is determined by the 25th and 75th percentiles, and the horizontal line and triangle within each box represent the median and mean, respectively. The CI represents the difference between the WT and the mutant, the complement, or the compared strain populations (log CFU per milliliter). A mean CI (triangle) significantly different than $0(* * *, P<0.05)$ denotes a competitive difference between the WT and the mutant, the complement, or the empty-vector-transformed strain. The data shown are from 4 independent experimental repetitions (WT$\operatorname{prgH}, n=50$; WT-complement, $n=48$; WT-prgH-pESV143 empty, $n=60$ insect homogenate samples).

nificantly lower levels than the WT (the mean CI was significantly different than $0 ; P<0.05$ ) in insect homogenate samples collected after the 24-h post-AAP (Fig. 3A). In the case of the WT-ssaK mutant comparison, no differences in recovered bacteria were observed in honeydew or homogenized insect samples collected at either the AAP or post-AAP (the mean CI was not significantly different than $0 ; P>0.05$ ) (Fig. 3B). A complemented $\operatorname{prgH} \mathrm{mu}-$ tant strain $\left(\Delta \operatorname{prgH}:: \mathrm{Cm}^{\mathrm{r}} \operatorname{prgH}\right.$-pEVS) was constructed and used to further evaluate the role of $\mathrm{prgH}$ in the survival of $\mathrm{S}$. enterica inside M. quadrilineatus. Consistent with previous results, the $\mathrm{prgH}$ mutant was recovered at significantly lower levels than the WT (the mean CI was significantly different than $0 ; P<0.05)$ in insect homogenate samples collected after the 24 -h post-AAP (Fig. 4). However, no differences in recovered bacteria were observed between the WT and the complemented strain in insect homogenate samples (the mean CI was not significantly different than $0 ; P>$ $0.05)$, indicating that complementation with $\mathrm{prgH}$ in trans restored S. enterica persistence in M. quadrilineatus (Fig. 4). Additionally, the $\operatorname{prgH}$ mutant transformed with the empty vector ( $\Delta$ prgH::: $\mathrm{Cm}^{\mathrm{r}}$-pEVS empty) was recovered at significantly lower levels than the WT (the mean CI was significantly different than 0 ;
$P<0.05)$ in insect homogenate samples, similar to the mutant without the plasmid (Fig. 4), demonstrating that carriage of the plasmid does not assist in colonization of the insect. These results demonstrate that $\operatorname{prgH}$, and therefore a functional SPI-1 T3SS, is important for persistence of S. enterica inside M. quadrilineatus.

The SPI-1 T3SS influences excretion and attenuates the persistence of $S$. enterica inside M. quadrilineatus. To investigate if S. enterica excretion correlated with recovery from within the insect, we performed matched-pair comparisons of individual $M$. quadrilineatus insects for the presence of $S$. enterica at the $24-\mathrm{h}$ AAP or post-AAP in honeydew or insect homogenate samples (Table 3). The comparisons examined the proportions of samples

TABLE 3 Matched-pair comparisons of correlated proportions of the presence of $S$. enterica in honeydew and/or homogenate samples of $M$. quadrilineatus fed mixed inocula of S. enterica T3SS mutants and the $\mathrm{WT}^{a}$

\begin{tabular}{|c|c|c|c|c|}
\hline \multirow[b]{2}{*}{ Matched pair of samples ${ }^{b}$} & \multicolumn{4}{|c|}{ Proportion $^{c}$} \\
\hline & -- & -+ & +- & ++ \\
\hline \multicolumn{5}{|l|}{ Wild type- $\Delta p r g H^{d}$} \\
\hline \multicolumn{5}{|l|}{ Wild type } \\
\hline $\begin{array}{l}\text { Honeydew } 24 \text {-h AAP-honeydew } \\
24 \mathrm{~h} \text { post-AAP }\end{array}$ & 0.01 & $(0.00$ & $0.13)$ & 0.86 \\
\hline $\begin{array}{l}\text { Honeydew 24-h AAP-insect } \\
\text { homogenate }\end{array}$ & 0.00 & $(0.01$ & $0.26)$ & 0.73 \\
\hline $\begin{array}{l}\text { Honeydew } 24 \text {-h post } \\
\text { AAP-insect homogenate }\end{array}$ & 0.01 & $(0.19$ & $0.23)$ & 0.57 \\
\hline \multicolumn{5}{|l|}{$\Delta \operatorname{prg} H:: \operatorname{Kan}^{\mathrm{r}}$} \\
\hline $\begin{array}{l}\text { Honeydew } 24 \text {-h AAP-honeydew } \\
24 \text {-h post-AAP }\end{array}$ & 0.01 & $(0.00$ & $0.20)$ & 0.79 \\
\hline $\begin{array}{l}\text { Honeydew 24-h AAP-insect } \\
\text { homogenate }\end{array}$ & 0.00 & $(0.01$ & $0.49)$ & 0.50 \\
\hline $\begin{array}{l}\text { Honeydew } 24-\mathrm{h} \\
\text { post-AAP-insect homogenate }\end{array}$ & 0.07 & $(0.14$ & $0.41)$ & 0.38 \\
\hline
\end{tabular}

Wild type- $\Delta s s a K^{e}$

Wild type

Honeydew 24-h AAP-honeydew 24-h post-AAP

Honeydew 24-h AAP-insect homogenate

Honeydew 24-h post-AAP-insect homogenate $\Delta s s a K:: \operatorname{Kan}^{\mathrm{r}}$

Honeydew 24-h AAP-honeydew $\quad 0.00 \quad\left(\begin{array}{llll}0.00 & 0.07\end{array}\right) \quad 0.93$ 24-h post-AAP

Honeydew 24-h AAP-insect homogenate

Honeydew 24-h post-AAP-insect homogenate

\begin{tabular}{llll}
0.00 & $(0.00$ & $0.05)$ & 0.95 \\
0.00 & $(\mathbf{0 . 0 0}$ & $\mathbf{0 . 3 0})$ & 0.70 \\
0.00 & $(0.05$ & $0.30)$ & 0.65 \\
& & & \\
0.00 & $(0.00$ & $0.07)$ & 0.93 \\
0.00 & $\mathbf{( 0 . 0 0}$ & $\mathbf{0 . 2 7})$ & 0.73 \\
0.02 & $(0.05$ & $0.25)$ & 0.68 \\
\hline
\end{tabular}

${ }^{a}$ Insects were fed an inoculated liquid diet for a 24-h AAP and then fed a noninoculated liquid diet for a 24 -h post-AAP.

${ }^{b}$ Matched-pair samples correspond to honeydew and insect homogenate samples obtained from individual insects fed a particular diet. Matched-pair comparisons are only in rows.

${ }^{c}$ The number listed is the proportion of the total samples observed with the given wildtype or mutant S. enterica contamination pattern. If the number of +- samples was significantly different than the number of -+ samples based on McNemar's test $(P \leq$ $0.01)$, the values are shown in boldface, and direct comparisons are made within parentheses only. The -- and ++ proportions are provided for reference purposes only and are not part of the chi-square comparison.

${ }^{d}$ Insects $(n=56)$ fed a mixed inoculum of wild-type and prgH mutant strains.

${ }^{e}$ Insects $(n=40)$ fed a mixed inoculum of wild-type and ssaK mutant strains. 
that were positive only for either the insect or honeydew samples at specific time points. High proportions of honeydew samples that were positive after both the AAP and the post-AAP $(++)$ were observed across strains. These results are consistent with our previous work (6) and demonstrated that insects that have access to an inoculated diet can excrete ingested bacteria during acquisition and even 24 and $48 \mathrm{~h}$ post-AAP. For the WT and the ssaK mutant, there were no differences between the proportions of honeydew samples that were positive only after the AAP $(+-)$ or the post-AAP $(-+)$. However, in the $\mathrm{prgH}$ mutant, a higher proportion of honeydew samples were positive after the 24-h AAP and negative after the 24-h post-AAP $(0.20)$ in comparison to samples in which the honeydew was negative after the AAP and positive after the post-AAP (0), demonstrating that the ingested $\mathrm{prgH}$ mutant was rapidly eliminated in insect excretion even during the acquisition period.

The comparison of S. enterica excretion and persistence inside M. quadrilineatus indicated that overall, insects that tested positive after homogenization had also excreted honeydew that was contaminated. This idea was reflected in the high proportion of double-positive samples (honeydew and insect homogenate) observed across strains. Moreover, the proportion of samples in which only the honeydew samples at $24 \mathrm{~h}$ AAP were positive was significantly higher than the proportion in which only the insect homogenate samples were positive. These results further demonstrate that not all of the ingested S. enterica bacteria are retained inside the insect and that a high proportion of bacteria are excreted in the honeydew. For the WT and the ssaK mutant, there were no differences in bacterial recovery at the 24-h post-AAP between the proportions in which exclusively the honeydew $(+-)$ or the insect homogenate $(-+)$ samples were positive. However, in the case of the $\operatorname{prgH}$ mutant, the proportion in which the honeydew but not the paired insect homogenate samples were positive was significantly higher than the proportion in which only the insect homogenate samples were positive, proving that the ingested $\mathrm{prgH}$ mutant was shed in the honeydew at a high frequency even by insects in which bacteria were not detected in insect homogenate samples.

prgH is expressed in the mid- and hindgut of M. quadrilineatus. To further investigate the involvement of $\mathrm{prgH}$ in S. enterica survival inside $M$. quadrilineatus, a $\mathrm{prgH}$ pProbeNT strain was constructed to monitor prgH expression in vivo. Insects $(n=122)$ were fed a $\mathrm{prgH}$ pProbeNT-inoculated liquid diet and dissected after either the 12-h AAP or the 24-and 48-h post-AAPs. Fluorescent cells were observed in $35 \%$ of insects sampled after the 12 -h AAP and in $16 \%$ and $18 \%$ of the insects sampled after the $24-$ or 48 -h post-AAP, respectively (Table 2 ). Confocal imaging of the dissected guts showed the presence of fluorescent bacteria in the mid- and hindguts of insects that were fed the prgH pProbeNTinoculated liquid diet (Fig. 5). These data confirm the expression of $\mathrm{prgH}$ in cells found in the mid- and hindguts of insects long after the acquisition period and passage of the inoculated sucrose solution.

To determine if $\operatorname{prgH}$ played a role in the localization of $S$. enterica in the alimentary canal of $M$. quadrilineatus, insects $(n=$ $84)$ were fed a GFP-labeled $\operatorname{prg} H$ mutant $\left(\Delta \operatorname{prg} H:: \mathrm{Cm}^{\mathrm{r}}-\mathrm{pKT}\right.$-kan $)$ inoculated liquid diet and dissected after either the 12-h AAP or the 24- and 48-h post-AAPs. Similar to our observations in the experiment with the WT (Fig. 1), fluorescent cells were mainly observed in the mid- and hindgut of M. quadrilineatus. However,

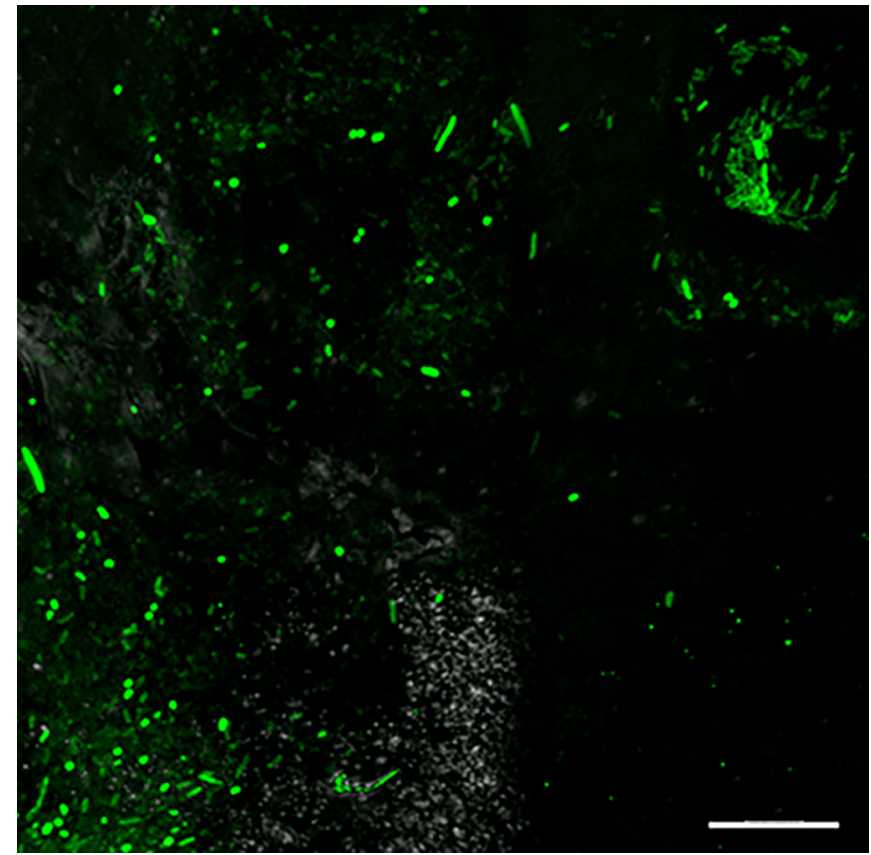

FIG 5 Expression of S. enterica prgH in the gut of $M$. quadrilineatus. Shown is a confocal micrograph of the dissected gut of an insect fed an S. entericainoculated liquid diet confined in a Parafilm sachet for a 12-h AAP and then moved to two consecutive noninoculated liquid diets for 24-h post-AAP each. Fluorescent $S$. enterica cells were observed in a portion of a midgut dissected after a 48-h post-AAP due to the green fluorescent protein transcribed from the $\mathrm{prgH}$ promoter from the plasmid pProbeNT. The experiment was repeated 5 times, and a total of 44 insects were dissected and examined. Scale bar, $20 \mu \mathrm{m}$.

the $\mathrm{prgH}$ mutant was observed at lower frequencies of $31 \%$ after the 12 -h AAP and $8 \%$ and $6 \%$ after the 24 - and 48 -h post-AAPs, respectively, than the WT (Table 2). These findings show that prgH influences the retention of S. enterica during passage through the gut of M. quadrilineatus and confirm our earlier conclusion of its importance for persistence. Because the fluorescent prgH mutant was observed throughout the experiment, these data suggest that $\mathrm{prgH}$ is not the sole factor that determines S. enterica localization inside the insect gut.

\section{DISCUSSION}

In this study, we demonstrated the presence and persistence of ingested $S$. enterica in the alimentary canal of M. quadrilineatus. The alimentary canal of insects is a continuous tube that connects the mouth to the anus through which ingested microorganisms are moved in the company of food. However, the harsh conditions encountered in the insect midgut (such as extreme $\mathrm{pH}$, presence of digestive enzymes, redox potential, and ionic strength) and the activation of defense mechanisms in response to foreign organisms normally inhibit the establishment and survival of ingested microorganisms $(25,26)$. Previous studies have shown successful gut migration of $S$. enterica in synanthropic and coprophagic insects (27-29). However, the fates of ingested bacteria varied significantly among species of insects, indicating that only certain species offer favorable conditions that allow movement and retention of S. enterica in the alimentary canal. Here, insect dissection revealed the presence of ingested $S$. enterica in the mid- and posterior portions of the alimentary canal of $M$. quadrilineatus, in- 
cluding organs such as the filter chamber, anterior and posterior midgut, and Malpighian tubules, even $48 \mathrm{~h}$ post-AAP. These results, and culture recovery of viable bacteria from honeydew and insect homogenates, indicate that $S$. enterica can survive passage through the midgut of this phytophagous hemipteran and that it is released in honeydew. Thus, the ability to survive internalization, gut transit, excretion, and deposition by M. quadrilineatus allows plant-associated S. enterica to maintain a cyclical lifestyle between insects and plants, which may enhance the maintenance of the human pathogen in agricultural environments.

Plant-associated S. enterica may establish temporary associations with $M$. quadrilineatus that allow retention within the insect and release onto plant surfaces. S. enterica was observed in the mid- and hindgut of $M$. quadrilineatus immediately after acquisition and up to $48 \mathrm{~h}$ post-AAP. Similar studies have also reported the occurrence of the enterobacteria P. stewartii and Erwinia tracheiphila in the mid- and hindguts of their vectors, the corn flea beetle and the striped cucumber beetle, Acalymma vittatum, respectively $(30,31)$. It is noteworthy that there was a significant reduction of $S$. enterica inside the insect during and after acquisition, evidenced by the differences in the frequencies of fluorescent bacteria observed in the guts of $M$. quadrilineatus dissected after a 12-h AAP or a 24- or 48-h post-AAP. We posit that this reduction could have been an effect of a lack of pathogen replication within the insect and its possible constant discharge in the honeydew. Overall, the persistence of S. enterica at low levels in M. quadrilineatus suggests that individual contaminated insects may serve as a point source of the human pathogen in association with plants over a short period, but the risk of long-term transmission by individual insects is low. Nevertheless, the aggregation behavior and short-distance dispersal on lettuce (32) indicate that $S$. enterica-contaminated leafhoppers could contaminate multiple leaves and adjacent plants even in a short period. Additionally, the fact that infestation with $M$. quadrilineatus enhanced the epiphytic survival of S. enterica on lettuce leaves (8) and that its honeydew can serve as a growth medium for the bacterium (J. P. Soto-Arias, R. L. Groves, and J. D. Barak, presented at the Food Research Institute annual meeting, Madison, WI, 21 to 22 May 2014) increases the chances of insect contamination, and therefore further dispersal of the pathogen on and among plants. Thus, this study further confirms that the most likely mode of transmission of ingested S. enterica by M. quadrilineatus implicates survival of the pathogen during passage through the alimentary canal and release in the environment in contaminated honeydew.

The presence of S. enterica in the Malpighian tubules up to $48 \mathrm{~h}$ post-AAP raises the possibility that persisting bacteria might escape from the insect digestive tract into the hemocoel. Various phytopathogenic bacteria have been shown to be capable of surviving and multiplying in specific hindgut regions of the pea aphid (Acyrthosiphon pisum), resulting in insect poisoning (33-36). We did not measure pathogen replication directly; however, the populations of fluorescent bacteria that were observed in the alimentary canal up to $48 \mathrm{~h}$ post-AAP lead us to hypothesize that $S$. enterica does not grow appreciably in the alimentary canal, and therefore, the potential pathogenicity of this human pathogen to M. quadrilineatus seems unlikely. Additionally, it is hypothesized that escaped bacteria will be successfully cleared in the M. quadrilineatus hemolymph, based on our observation that in some cases fluorescent bacteria that were in contact with the hemolymph after dissection were phagocytosed by insect hemocytes (data not shown). Previous studies have demonstrated the ability of various insects to clear bacteria, such as Staphylococcus aureus, Listeria spp., Escherichia coli K-12, and Bacillus subtilis, from the hemolymph after bacterial injection into the hemocoel (37-39). S. enterica infection via septic challenge and persistence in the hemolymph of live leafhoppers warrant closer examination.

The complex microbiota of M. quadrilineatus may influence the fate of ingested S. enterica. M. quadrilineatus possesses two obligate symbionts (Sulcia muelleri and Nasuia deltocephalinicola) that provide essential amino acids that the insect is unable to synthesize or obtain in sufficient quantities from plant phloem (40). Recent studies of endosymbiotic microbiota in natural populations of Macrosteles leafhoppers (Macrosteles striifrons and Macrosteles sexnotatus) have revealed the coexistence of obligate and facultative endosymbionts with phytopathogenic phytoplasmas, as well as other enteric bacteria (41), suggesting that these endosymbionts may encourage leafhopper colonization by enterics. In contrast, insect resistance to various pathogens and parasites and activation of an immune response against foreign intruders have been associated with the presence of endosymbiotic bacteria (4244), so endosymbionts can limit the survival of enterics, such as $S$. enterica, within leafhoppers. The presence and persistence of ingested S. enterica in the alimentary canal of M. quadrilineatus suggests that the pathogen may interact with coexisting endosymbionts, and future studies can reveal whether these interactions can positively or negatively affect the retention and transmission of $S$. enterica by the leafhopper.

The SPI-1 T3SS allows S. enterica persistence, colonization, and pathogenicity in multiple hosts. The SP1-1 family of T3SSs has been found in several animal/human (S. enterica, E. coli, Shigella spp., and Yersinia pestis)- and plant (Erwinia spp., Xanthomonas spp., and P. stewartii)-pathogenic bacteria (45). Additionally, the presence of homologs of the SPI-1 T3SS in insect symbionts, including Hamiltonella defensa and S. glossinidius, implies that SPI-1 may be necessary for persistence inside insect hosts $(10,13,45)$. Similarly, P. stewartii carries an SPI-1 T3SS required for persistence in the gut of its insect vector and successful transmission of the pathogen to its ultimate plant host (14). In the case of S. enterica, the SPI-1 T3SS has multiple roles: (i) invasion of mammalian host epithelial cells (13) and (ii) suppression or activation of plant defenses of the model plants Arabidopsis thaliana, Nicotiana tabacum, and Medicago spp. $(16,46,47)$. In this study, the $\operatorname{prgH}$ mutant, which lacks a functional SPI-1 T3SS (21), was defective in persistence in M. quadrilineatus. Thus, our results suggest that, in addition to animal pathogenicity and plant defense regulation, the SPI-1-encoded T3SS also impacts the retention of $S$. enterica inside its potential vector, $M$. quadrilineatus. In contrast, the SPI-2 T3SS is not involved in this vector interaction.

S. enterica $\operatorname{prgH}$ is expressed in the mid- and hindgut of $M$. quadrilineatus and appears to be required for persistence in this vector. $\operatorname{PrgH}$, in combination with $\operatorname{PrgK}$ and $\mathrm{InvG}$, has been shown to compose the essential multiring base structure of the T3SS needle complex necessary to export effector proteins into host cells (48). Both PrgH and PrgK, in addition to PrgI, PrgJ, OrgA, and OrgB, are required for S. enterica entry into host cells (21). It is possible that in this study the lack of $p r g H$, and thus the absence of the T3SS needle structure, precluded S. enterica from delivering effector proteins necessary to manipulate and invade insect cells. However, this hypothesis may be improbable based on the fact that populations greater than $10^{4} \mathrm{CFU} / \mathrm{ml}$ of the WT strain 
were only occasionally recovered from homogenized insects postacquisition. Thus, $S$. enterica may be retained at low titers without invasion of specific organs, in a manner similar to some insect symbionts, such as $H$. defensa (10). Additionally, it is noteworthy that the disruption of the $\mathrm{prgH}$ gene and replacement with the insertion of the $\mathrm{Cm}$ resistance cassette could have had a polar effect affecting the transcription of the downstream genes that share the same operon (prgIJK). However, the fact that we were able to complement the mutant phenotype with $\mathrm{prgH}$ alone and not the whole operon suggests that prgIJK are expressed normally in the $\operatorname{prgH}$ mutant $\left(\Delta p r g H:: \mathrm{Cm}^{\mathrm{r}}\right)$ and there is no polar effect or that these other genes have no effect on the persistence of the pathogen in this vector. Besides a role in host invasion, S. enterica SPI-1 has also been associated with bacterial adhesion and clumping in media, which demonstrated the possibility of T3SS-mediated bacterial aggregation outside eukaryotic host cells (49). Induction of $\mathrm{prgH}$ expression was observed in the mid- and hindgut of $M$. quadrilineatus for up to $48 \mathrm{~h}$ post-AAP, and the $p r g H$ mutant had low retention during gut passage and persistence postacquisition compared to the WT. These results suggest that the SPI-1 T3SS needle may influence S. enterica attachment and the formation of modest cell aggregates on the surfaces of insect organs and tissues, preventing the elimination of bacteria in insect excretions. Interestingly, match-paired comparison of individual M. quadrilineatus insects demonstrated that the $\mathrm{prgH}$ mutant was shed in the honeydew at a high frequency even in insects from which $S$. enterica was not recovered after insect homogenization. This finding suggests that the SPI-1 T3SS needle may affect transmission, since the absence of the needle complex increased shedding up to $24 \mathrm{~h}$ post-AAP, which might decrease the chance of the insect spreading the bacterium to other plants due to premature shedding of the bacterium prior to movement. Further studies are necessary to investigate the roles of specific effector proteins that are delivered by the SPI-1 T3SS in bacterial attachment, aggregation, and persistence inside $M$. quadrilineatus and transmission to and among plants.

Overall, this study provides novel evidence of the presence and persistence of S. enterica in a potential insect vector and sheds light on the possibility that in agricultural environments, plant-associated human pathogens may establish opportunistic associations with phytophagous insects that ultimately allow them to reach and colonize new host plants. However, future studies are necessary to advance our knowledge of the potential symbiotic interaction between plant-associated human bacterial pathogens and phytophagous insects, the implications of this association in bacterial and insect environmental fitness, and the contribution to fresh produce contamination and human disease.

\section{ACKNOWLEDGMENTS}

This work was partially supported by a USDA-Hatch grant (WIS01574) to J.D.B. and R.L.G. and by the Food Research Institute, University of Wisconsin (UW)-Madison. J.P.D.-A. was partially supported by a UWMadison Distinguished Graduate Student Fellowship.

We especially thank Selah Adonai Zaldarriaga and the Biomedical and Premedical Illustration Program at Iowa State University for the leafhopper intestinal tract illustration (Fig. 1A) and Lance Rodenkirch at the W. M. Keck Laboratory for Biological Imaging and Howard Berg at the Donald Danforth Plant Science Center's Integrated Microscopy Facility for the use of and assistance with their confocal microscopes. We also thank Nicholas Keuler of the College of Agriculture and Life Sciences' Statistical Consulting Laboratory, UW-Madison, for his assistance with statistical analysis. We are grateful to Kimberly Cowles and Lyric Bartholomay for providing constructive criticism on earlier versions of the manuscript.

\section{REFERENCES}

1. Centers for Disease Control and Prevention. 3 April 2015. What is salmonellosis? Centers for Disease Control and Prevention, Atlanta, GA. http://www.cdc.gov/salmonella/general/index.html.

2. Heaton JC, Jones K. 2008. Microbial contamination of fruit and vegetables and the behaviour of enteropathogens in the phyllosphere: a review. J Appl Microbiol 104:613-626. http://dx.doi.org/10.1111/j.1365-2672 .2007.03587.x.

3. Barak JD, Schroeder B. 2012. Interrelationships of food safety and plant pathology: the life cycle of human pathogens. Annu Rev Phytopathol 50: 241-266. http://dx.doi.org/10.1146/annurev-phyto-081211-172936.

4. Islam M, Morgan J, Doyle MP, Phatak SC, Millner P, Jiang X. 2004. Persistence of Salmonella enterica serovar Typhimurium on lettuce and parsley and in soils on which they were grown in fields treated with contaminated manure composts or irrigation water. Foodborne Pathog Dis 1:27-35. http://dx.doi.org/10.1089/153531404772914437.

5. Wales AD, Carrique-Mas JJ, Rankin M, Bell B, Thind BB, Davies RH. 2010. Review of the carriage of zoonotic bacteria by arthropods, with special reference to Salmonella in mites, flies and litter beetles. Zoonoses Public Health 57:299-314. http://dx.doi.org/10.1111/j.1863-2378.2008 .01222.x.

6. Soto-Arias JP, Groves RL, Barak JD. 2014. Transmission and retention of Salmonella enterica by phytophagous hemipteran insects. Appl Environ Microbiol 80:5447-5456. http://dx.doi.org/10.1128/AEM.01444-14.

7. Painter JA, Hoekstra RM, Ayers T, Tauxe RV, Braden CR, Angulo FJ, Griffin PM. 2013. Attribution of foodborne illnesses, hospitalizations, and deaths to food commodities by using outbreak data, United States, 1998-2008. Emerg Infect Dis 19:407-415. http://dx.doi.org/10.3201/eid1 903.111866. http://dx.doi.org/10.3201/eid1903.111866.

8. Soto-Arias JP, Groves R, Barak JD. 2013. Interaction of phytophagous insects with Salmonella enterica on plants and enhanced persistence of the pathogen with Macrosteles quadrilineatus infestation or Frankliniella occidentalis feeding. PLoS One 8:e79404. http://dx.doi.org/10.1371/journal .pone.0079404.

9. Nadarasah G, Stavrinides J. 2011. Insects as alternative hosts for phytopathogenic bacteria. FEMS Microbiol Rev 35:555-575. http://dx.doi.org /10.1111/j.1574-6976.2011.00264.x.

10. Moran NA, Degnan PH, Santos SR, Dunbar HE, Ochman H. 2005. The players in a mutualistic symbiosis: Insects, bacteria, viruses, and virulence genes. Proc Natl Acad Sci U S A 102:16919-16926. http://dx.doi.org/10 $.1073 /$ pnas.0507029102.

11. Cornelis GR. 2006. The type III secretion injectisome. Nat Rev Microbiol 4:811-825. http://dx.doi.org/10.1038/nrmicro1526.

12. Ly KT, Casanova JE. 2007. Mechanisms of Salmonella entry into host cells. Cell Microbiol 9:2103-2111. http://dx.doi.org/10.1111/j.1462-5822 .2007.00992.x.

13. Dale C, Young SA, Haydon DT, Welburn SC. 2001. The insect endosymbiont Sodalis glossinidius utilizes a type III secretion system for cell invasion. Proc Natl Acad Sci U S A 98:1883-1888. http://dx.doi.org/10 .1073/pnas.98.4.1883

14. Correa VR, Majerczak DR, el-Ammar D, Merighi M, Pratt RC, Hogenhout SA, Coplin DL, Redinbaugh MG. 2012. The bacterium Pantoea stewartii uses two different type III secretion systems to colonize its plant host and insect vector. Appl Environ Microbiol 78:6327-6336. http://dx .doi.org/10.1128/AEM.00892-12.

15. Schleker S, Kshirsagar M, Klein-Seetharaman J. 2015. Comparing human-Salmonella with plant-Salmonella protein-protein interaction predictions. Front Microbiol 6:45. http://dx.doi.org/10.3389/fmicb.2015 .00045 .

16. Schikora A, Virlogeux-Payant I, Bueso E, Garcia AV, Nilau T, Charrier A, Pelletier S, Menanteau P, Baccarini M, Velge P, Hirt H. 2011. Conservation of Salmonella infection mechanisms in plants and animals. PLoS One 6:e24112. http://dx.doi.org/10.1371/journal.pone.0024112.

17. Barak JD, Whitehand LC, Charkowski AO. 2002. Differences in attachment of Salmonella enterica serovars and Escherichia coli O157:H7 to alfalfa sprouts. Appl Environ Microbiol 68:4758-4763. http://dx.doi.org/10 .1128/AEM.68.10.4758-4763.2002.

18. Miller WG, Leveau JH, Lindow SE. 2000. Improved gfp and inaZ broad- 
host-range promoter-probe vectors. Mol Plant Microbe Interact 13:12431250. doi.org/10.1094/MPMI.2000.13.11.1243. http://dx.doi.org/10.1094 /MPMI.2000.13.11.1243.

19. Santiviago CA, Reynolds MM, Porwollik S, Choi SH, Long F, AndrewsPolymenis HL, McClelland M. 2009. Analysis of pools of targeted Salmonella deletion mutants identifies novel genes affecting fitness during competitive infection in mice. PLoS Pathog 5:e1000477. http://dx.doi.org /10.1371/journal.ppat.1000477.

20. Gemski P, Jr, Stocker BA. 1967. Transduction by bacteriophage P22 in nonsmooth mutants of Salmonella typhimurium. J Bacteriol 93:15881597.

21. Klein JR, Fahlen TF, Jones BD. 2000. Transcriptional organization and function of invasion genes within Salmonella enterica serovar Typhimurium pathogenicity island 1, including the $\operatorname{prgH}, \operatorname{prgI}, \operatorname{prgJ}, \operatorname{prgK}, \operatorname{org} A$, $\operatorname{org} B$, and $\operatorname{org} C$ genes. Infect Immun 68:3368-3376. http://dx.doi.org/10 .1128/IAI.68.6.3368-3376.2000.

22. Hensel M, Shea JE, Raupach B, Monack D, Falkow S, Gleeson C, Kubo T, Holden DW. 1997. Functional analysis of $s s a J$ and the $s s a K / U$ operon, 13 genes encoding components of the type III secretion apparatus of Salmonella pathogenicity island 2. Mol Microbiol 24:155-167. http://dx.doi .org/10.1046/j.1365-2958.1997.3271699.x.

23. Gil-Fernandez C, Black LM. 1965. Some aspects of the internal anatomy of the leafhopper Agallia constricta (Homoptera: Cicadellidae). Ann Entomol Soc Am 58:275-284. http://dx.doi.org/10.1093/aesa/58.3.275.

24. Beuzón CR, Holden DW. 2001. Use of mixed infections with Salmonella strains to study virulence genes and their interactions in vivo. Microbes Infect 3:1345-1352. http://dx.doi.org/10.1016/S1286-4579(01)01496-4.

25. Engel P, Moran NA. 2013. The gut microbiota of insects-diversity in structure and function. FEMS Microbiol Rev 37:699-735. http://dx.doi .org/10.1111/1574-6976.12025.

26. Vallet-Gely I, Lemaitre B, Boccard F. 2008. Bacterial strategies to overcome insect defences. Nat Rev Microbiol 6:302-313. http://dx.doi.org/10 $.1038 /$ nrmicro1870.

27. Zheng L, Crippen TL, Sheffield CL, Poole TL, Yu Z, Tomberlin JK. 2012. Evaluation of Salmonella movement through the gut of the lesser mealworm, Alphitobius diaperinus (Coleoptera: Tenebrionidae). Vector Borne Zoonotic Dis 12:287-292. http://dx.doi.org/10.1089/vbz.2011 .0613 .

28. Greenberg B, Kowalski JA, Klowden MJ. 1970. Factors affecting the transmission of Salmonella by flies: natural resistance to colonization and bacterial interference. Infect Immun 2:800-809.

29. Julseth RM, Felix JK, Burkholder WE, Deibel RH. 1969. Transmission of Enterobacteriaceae by insects: fate of Salmonella fed to the hide beetle Dermestes maculatus and a novel method for mounting insects. Appl Microbiol 17:710-713.

30. el-Ammar D, Correa VR, Hogenhout SA, Redinbaugh MG. 2014. Immunofluorescence localization and ultrastructure of Stewart's wilt disease bacterium Pantoea stewartii in maize leaves and in its flea beetle vector Chaetocnema pulicaria (Coleoptera: Chrysomelidae). J Microsc Ultrastruct 2:28-33. http://dx.doi.org/10.1016/j.jmau.2014.01.001.

31. Garcia-Salazar C, Gildow FE, Fleicher SJ, Cox-Foster D, Luckezic FL. 2000. ELISA vs. immunolocalization to determine the association of Erwinia tracheiphila in Acalymma vittatum (Coleoptera: Chrysomelidae). Environ Entomol 29:542-550. http://dx.doi.org/10.1603/0046-225X-29.3 .542 .

32. Zhou L, Hoy CW, Miller SA, Nault LR. 2003. Marking methods and field experiments to estimate aster leafhopper (Macrosteles quadrilineaus) dispersal rates. Environ Entomol 32:1177-1186. http://dx.doi.org/10.1603 /0046-225X-32.5.1177.

33. Stavrinides J, No A, Ochman H. 2010. A single genetic locus in the phytopathogen Pantoea stewartii enables gut colonization and pathogenicity in an insect host. Environ Microbiol 12:147-155. http://dx.doi.org /10.1111/j.1462-2920.2009.02056.x.
34. Stavrinides J, McCloskey JK, Ochman H. 2009. Pea aphid as both host and vector for the phytopathogenic bacterium Pseudomonas syringae. Appl Environ Microbiol 75:2230-2235. http://dx.doi.org/10.1128/AEM .02860-08.

35. Grenier AM, Duport G, Pages S, Condemine G, Rahbe Y. 2006. The phytopathogen Dickeya dadantii (Erwinia chrysanthemi 3937) is a pathogen of the pea aphid. Appl Environ Microbiol 72:1956-1965. http://dx.doi .org/10.1128/AEM.72.3.1956-1965.2006.

36. Harada H, Ishikawa H. 1997. Experimental pathogenicity of Erwinia aphidicola to pea aphid, Acyrthosiphon pisum. J Gen Appl Microbiol 43: 363-367. http://dx.doi.org/10.2323/jgam.43.363.

37. Altincicek B, Ter Braak B, Laughton AM, Udekwu KI, Gerardo NM. 2011. Escherichia coli K-12 pathogenicity in the pea aphid, Acyrthosiphon pisum, reveals reduced antibacterial defense in aphids. Dev Comp Immunol 35:1091-1097. http://dx.doi.org/10.1016/j.dci.2011.03.017.

38. Mukherjee K, Altincicek B, Hain T, Domann E, Vilcinskas A, Chakraborty T. 2010. Galleria mellonella as a model system for studying Listeria pathogenesis. Appl Environ Microbiol 76:310-317. http://dx.doi .org/10.1128/AEM.01301-09.

39. Haine ER, Moret Y, Siva-Jothy MT, Rolff J. 2008. Antimicrobial defense and persistent infection in insects. Science 322:1257-1259. http://dx.doi .org/10.1126/science.1165265.

40. Bennett GM, Moran NA. 2013. Small, smaller, smallest: the origins and evolution of ancient dual symbioses in a phloem-feeding insect. Genome Biol Evol 5:1675-1688. http://dx.doi.org/10.1093/gbe/evt118.

41. Ishii Y, Matsuura Y, Kakizawa S, Nikoh N, Fukatsu T. 2013. Diversity of bacterial endosymbionts associated with Macrosteles leafhoppers vectoring phytopathogenic phytoplasmas. Appl Environ Microbiol 79:50135022. http://dx.doi.org/10.1128/AEM.01527-13.

42. Eleftherianos I, Atri J, Accetta J, Castillo JC. 2013. Endosymbiotic bacteria in insects: guardians of the immune system? Front Physiol 4:46. http://dx.doi.org/10.3389/fphys.2013.00046.

43. Scarborough CL, Ferrari J, Godfray HC. 2005. Aphid protected from pathogen by endosymbiont. Science 310:1781. http://dx.doi.org/10.1126 /science. 1120180 .

44. Oliver KM, Russell JA, Moran NA, Hunter MS. 2003. Facultative bacterial symbionts in aphids confer resistance to parasitic wasps. Proc Natl Acad Sci U S A 100:1803-1807. http://dx.doi.org/10.1073/pnas .0335320100

45. Egan F, Barret M, O'Gara F. 2014 The SPI-1-like type III secretion system: more roles than you think. Front Plant Sci 5:34. http://dx.doi.org /10.3389/fpls.2014.00034.

46. Shirron N, Yaron S. 2011. Active suppression of early immune response in tobacco by the human pathogen Salmonella typhimurium. PLoS One 6:e18855. http://dx.doi.org/10.1371/journal.pone.0018855.

47. Iniguez AL, Dong Y, Carter HD, Ahmer BM, Stone JM, Triplett EW. 2005. Regulation of enteric endophytic bacterial colonization by plant defenses. Mol Plant Microbe Interact 18:169-178. http://dx.doi.org/10 1094/MPMI-18-0169.

48. Kubori T, Matsushima Y, Nakamura D, Uralil J, Lara-Tejero M, Sukhan A, Galán JE, Aizawa S-I. 1998. Supramolecular structure of the Salmonella typhimurium type III protein secretion system. Science 280: 602-605. http://dx.doi.org/10.1126/science.280.5363.602.

49. Jennings ME, Quick LN, Ubol N, Shrom S, Dollahon N, Wilson JW. 2012. Characterization of Salmonella type III secretion hyper-activity which results in biofilm-like cell aggregation. PLoS One 7:e33080. http: //dx.doi.org/10.1371/journal.pone.0033080.

50. Bose JL, Rosenberg CS, Stabb EV. 2008. Effects of luxCDABEG in Vibrio fisheri: enhancement of symbiotic colonization and conditional attenuation of growth in culture. Arch Micobiol 190:169-183. http://dx.doi.org /10.1007/s00203-008-0387-1. 